\title{
Een patiënte met abdominale last en anorexie
}

\author{
W. VAn Moerkercke ${ }^{1,4}$, G. Deboever ${ }^{2}$, K. Hertveldt ${ }^{3}$
}

\section{Casus}

Een 72-jarige vrouw werd naar de dienst Gastro-Enterologie verwezen wegens abdominale ongemakken en obstipatieklachten. Ze had een vage epigastrische last gepaard met anorexie.

Bij de anamnese vermeldde ze een keizersnede en een cholecystectomie.

Biochemisch screeningsonderzoek kon geen richtinggevende afwijkingen aantonen. Het hemoglobinegehalte was 11,3 g/dl (normaal: 12,0-16,0) met een „mean corpuscular volume" (MCV) van 90,3 fl (normaal: 80-100) en een "mean corpuscular hemoglobin” $(\mathrm{MCH})$ van 28,2 pg (normaal: 26-34). De creatininemie bedroeg $1,13 \mathrm{mg} / \mathrm{dl}$ (normaal: 0,0-0,9). Enkel de gamma-glutamyltransferase(GGT)-fractie was verhoogd: $73 \mathrm{U} / 1$ (normaal: 0-33).

Endoscopisch onderzoek toonde verscheidene zones die submucosaal geïnfiltreerd en substenotisch voorkwamen, zowel ter hoogte van het antrale gedeelte van de maag als van het caecum en het sigmoïd. Een computertomografie (CT) van het abdomen toonde een focale wandverdikking ter hoogte van het maagantrum en het sigmoïd, maar ook ter hoogte van het colon transversum (fig. 1). Het beeld deed het vermoeden van peritoneale metastasering rijzen.

\section{Wat is uw diagnose?}

1 Interne Geneeskunde,

2 Dienst Gastro-Enterologie,

3 Dienst Pathologische Ontleedkunde, AZ Damiaan Oostende.

4 Correspondentieadres: dr. W. Van Moerkerke, Zwevezelestraat 100, 8810 Lichtervelde; e-mail: wouter.vanmoerkercke@scarlet.be
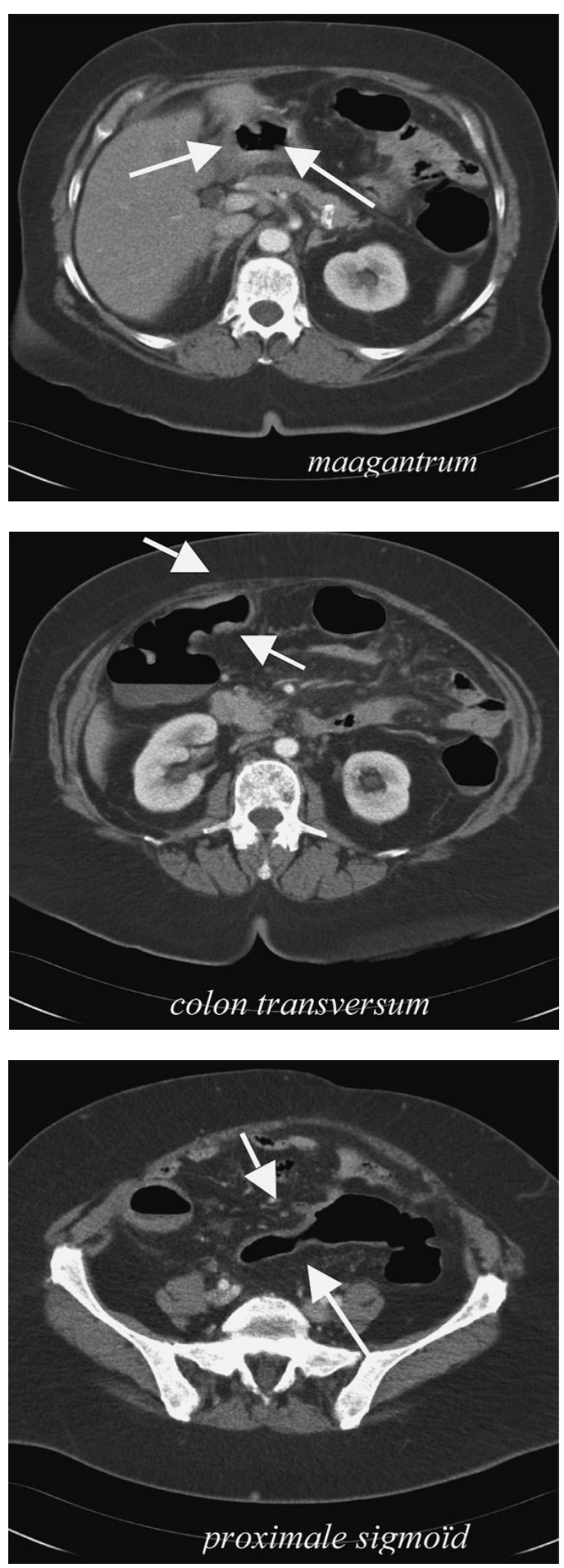

Fig. 1: Computertomografie van het abdomen. 


\section{Bespreking}

De endoscopisch genomen biopten kwamen overeen met metastasen van een lobulair borstcarcinoom. Sommige tumorale cellen hadden een zegelringceldifferentiatie. Immunohistochemisch was de tumorale populatie positief voor CKBS (breedspectrumcytokeratine), wat bevestigde dat de letsels metastasen van een carcinoom waren. De tumorcellen toonden tevens een matige tot sterke nucleaire positiviteit voor oestrogeen- (ER) en progesteronreceptoren (PR), wat het pathologisch-anatomisch bewijs vormde voor de mammaire origine van de metastasen (fig. 2).

Klinisch onderzoek bevestigde de aanwezigheid van een tumorale massa in de rechterborst met axillaire adenopathieën. Een mammografie anderhalf jaar geleden werd als normaal geprotocolleerd.

$\mathrm{Na}$ verdere stagering werd besloten tot een $\mathrm{cT}_{4} \mathrm{~N}_{2} \mathrm{M}_{1}$ hormoongevoelig gemetastaseerd borstcarcinoom. Het CA15-3 bedroeg $229 \mathrm{U} / \mathrm{ml}$. Hormoontherapie onder de vorm van tamoxifen (een selectieve oestrogeenreceptormodulator (Nolvadex $\left.{ }^{\circledR}\right)$ ) werd gestart.

In de literatuur beschrijft men metastasering van een borstcarcinoom naar ieder niveau van de gastro-intestinale tractus, doch meestal naar het proximale deel (vooral de maag). Ter hoogte van de maag treft men meestal een diffuse infiltratie van de maagwand aan, zoals bij een linitis plastica. In de dikke darm zijn de meeste metastasen ter hoogte van het proximale colon en het rectosigmoïd gelokaliseerd (1). De metastasen kunnen alle lagen van de darmwand infiltreren, maar het minst vaak de mucosa. In onze casus waren zowel de letsels van de maag als van het colon volledig submucosaal gelokaliseerd.

De meest voorkomende primaire borsttumor is deze van het ductale type, maar vooral de minder vaak voorkomende lobulaire carcinomen hebben de tendens om naar de gastro-intestinale tractus te metastaseren $(2,3)$. De reden hiervoor is niet duidelijk (4). Bovendien stelt men bij primaire borsttumoren van het gemengde type vooral de lobulaire component aan in de metastasen (5).

Meestal wordt de metastasering naar de gastro-intestinale tractus bij autopsie aangetroffen (15-35\%), minder vaak in vivo $(<1 \%)(2,6,7)$. De overgrote meerderheid van de gastro-intestinale metastasen blijft immers asymptomatisch. Symptomen treden pas op ten gevolge van een massa-effect, met (sub)obstructieklachten tot gevolg. Minder vaak bemerkt men een ulceratief letsel met bloeding, wat zich naargelang de aangetaste zone kan uiten als melaena of rood bloedverlies per anum.

Bij patiënten met een borstcarcinoom in de voorgeschiedenis is het belangrijk voor ogen te houden dat gastro-intestinale symptomatologie niet alleen een neveneffect van chemotherapie kan zijn, maar dat een onderliggende metastasering naar het maag-darmkanaal verantwoordelijk kan zijn voor de klachten (8). In deze casus lag de situatie iets anders: de diagnose van borstcarcinoom werd pas gesteld ten gevolge van de metastasering naar de gastro-intestinale tractus. Bij aanwezigheid van
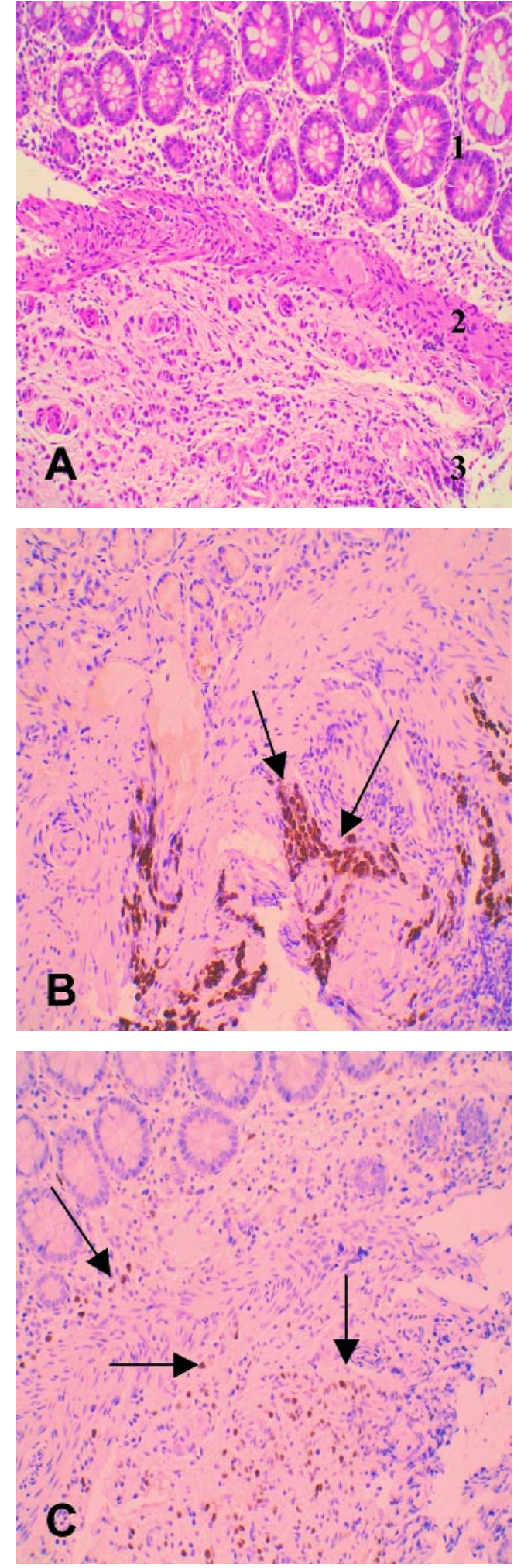

Fig. 2: Pathologisch-anatomische onderzoeken.

A. HE-kleuring colon (vergroting: $200 \times$ ) met 1: mucosa, 2: muscularis mucosae, 3 : submucosa.

B. CKBS-kleuring maag (vergroting: $200 \times$ ): cytoplasmatische aankleuring.

C. ER-kleuring colon (vergroting: $200 \times$ ): nucleaire aankleuring. 
multipele extrinsieke letsels in het maag-darmkanaal bij een patiënte met een borstcarcinoom in de voorgeschiedenis moet men bedacht zijn op een gemetastaseerde ziekte (1). De niet-specifieke klachten en de variabele radiografische bevindingen bemoeilijken de diagnostiek (9). Vergelijking van het immunohistochemisch onderzoek van de metastatische lokalisatie met het primaire borstcarcinoom is essentieel. Vooral het nagaan van de receptorstatus is richtinggevend voor de diagnostiek.

Het inschakelen van een systemische therapie levert de beste resultaten op, en zorgt ervoor dat chirurgie een minder noodzakelijke optie hoeft te zijn (9). Het betreft echter steeds een palliatieve setting.

\section{Abstract \\ A woman with progressive anorexia}

A 72-year-old woman was referred to the Department of Gastroenterology because of complaints of abdominal pain, anorexia and constipation. An endoscopical evaluation of the gastro-intestinal tract revealed diffuse submucosal lesions, from which biopsies were taken.

Further investigations confirmed a metastasized lobular breast carcinoma. According to the literature gastrointestinal tract metastases are only rarely the first manifestation of a breast cancer. In our case it was important to differentiate with a primary gastrointestinal malignancy.

The reason why the primary tumor is almost always a breast carcinoma of the lobular type, remains unknown.

\section{Literatuur}

1. Dhar S, Kulaylat M, Gordon K, Lall P, Doerr RJ. Solitary papillary breast carcinoma metastasis to the large bowel presenting as primary colon carcinoma: case report and review of the literature. Am Surg 2003; 69: 799-803.

2. Reiman T, Butts CA. Upper gastrointestinal bleeding as a metastatic manifestation of breast cancer: a case report and review of the literature. Can J Gastroenterol 2001; 15: 67-71.

3. Voravud N, el-Naggar AK, Balch CM, Theriault RL. Metastatic lobular breast carcinoma simulating primary colon cancer. Am J Clin Oncol 1992; 15: 365-369.

4. Bamias A, Baltayiannis G, Kamina $\mathrm{S}$, et al. Rectal metastases from lobular carcinoma of the breast: report of a case and literature review. Ann Oncol 2001; 12: 715-718.

5. Clavien PA, Laffer U, Torhost J, Harder F. Gastro-intestinal metastases as first clinical manifestation of the dissemination of a breast cancer. Eur J Surg Oncol 1990; 16: 121-126.

6. SHImonov M, RuBin M. Metastatic breast tumors imitating primary colonic malignancies. Isr Med Assoc J 2000; 2: 863-864.

7. LotTini M, Neri A, Vuolo G, et al. Duodenal obstruction from isolated breast cancer metastasis: a case report. Tumori 2002; 88: 427-429.

8. Schwarz RE, Klimstra DS, Turnbull AD. Metastatic breast cancer masquerading as gastrointestinal primary. Am J Gastroenterol 1998; 93: 111-114.

9. TaAl BG, den Hartog Jager FC, Steinmetz R, Peterse H. The spectrum of gastrointestinal metastases of breast carcinoma: II. The colon and rectum. Gastrointest Endosc 1992; 38: 136-141. 